are being made for emergency delivery. If resuscitation occurs within five minutes delivery may be undertaken with reasonable confidence.

We thank Dr J R Kemp and the staff of the rhesus isoimmunisation centre at Lewisham Hospital for referring the patient and providing us with donor blood; and Drs H R Gamsu and W J Fysh, who managed the neonate at the neonatal unit at King's College Hospital.

D'Souza SW. Neurodevelopmental outcome after birth asphyxia. In Chiswick ML, ed. Recent advances in perinatal medicine. Edinburgh : Churchill Livingstone, 1983:137-52.

? Rodeck CH, Holman CA, Karnicki J, et al. Direct intravascular fetal blood transfusion by fetoscopy in severe rhesus isoimmunisations. Lancet 1981; i:625-7.

"Liley AW. Liquor amnii analysis in the management of the pregnancy complicated by rhesus serialisation. Am $\mathcal{F}$ Obstet Gynecol 1961;82: 1359-70.

' Campbell S, Pearce JM. Ultrasound visualisation of congenital malformations. Br Med Bull 1983;39:322-31.

s Rodeck $\mathrm{CH}$, Nicolaides KH, Warsof SC, it al. The management of severe rhesus isoimmunisation by fetoscopic intravascular transfusion. Am $\mathcal{F}$ Obstet Gynecol (in press).

(Accepted 21 December 1983)

Harris-Birthright Research Centre for Fetal Medicine, Department of Obstetrics and Gynaecology, King's College School of Medicine and Dentistry, London SE5 8RX

K H NICOLAIDES, BSC, $\mathrm{MB}$, lecturer

C H RODECK, BSC, MRCOG, director

Correspondence to: Dr K H Nicolaides.

\section{Dicyclomine: worrying symptoms associated with its use in some small babies}

Dicyclomine is a smooth muscle antispasmodic frequently prescribed during infancy for alleged "colic." We report two cases in which dramatic respiratory events were associated with ingestion of the drug.

\section{Case reports}

Case 1-A 6 week old girl was given a very snall amount of Merbentyl (Merrell Pharmaceuticals) on a spoon. She became transiently apnoeic and pale but recovered quickly. The next day the full prescribed dose of $5 \mathrm{ml}$ was administered. She again became apnoeic and subsequently cyanosed. She recovered during the ambulance journey to hospital while receiving mouth to mouth resuscitation. Subsequent examination showed no abnormality. The electrocardiogram was normal.

Case 2-A 5 week old girl was given the prescribed dose of Merbentyl and immediately became pale, rigid, and apnoeic. She recovered quickly without resuscitation. An identical though more dramatic and prolonged symptom complex occurred after the next dose and the medication was discontinued by the mother. No abnormalities were subsequently identified on examination.

\section{Comment}

The explanation for these apparent side effects of dicyclomine is obscure. The immediacy of effect suggests an idiosyncratic local action, perhaps at laryngeal level. It was not possible to exclude inhalation but there was no clinical evidence to support this. Both children had previously taken other medications from a spoon without difficulty.

The product manufacturers' data sheet specifies that this preparation should be used with caution in infants of under 6 weeks of age and lists breathing difficulties including breathlessness, respiratory collapse and apnoea, seizures, syncope, asphyxia, muscular hypotonia, and coma as possible though rare complications in this age group. This information is based on four cases reported to the manufacturer in the past 10 years. All four infants were 3 weeks of age and all had dramatic respiratory symptoms immediately after ingestion of a dicyclomine preparation. The symptoms lasted up to 30 minutes in two of the children. All recovered normally (Merrell Pharmaceuticals Ltd, personal communication). Four notifications of a similar pattern of events have been made to the Committee on the Safety of Medicines (personal communication). All four children were under 7 weeks of age and all recovered normally.
These potential side effects do not appear to be widely recognised and are not noted in the current edition of the British National Formulary. Underreporting may therefore be common. It seems prudent to review carefully any infant with reported respiratory problems temporally associated with the administration of dicyclomine and specifically discourage its use in infants under 6 weeks of age. In older infants a maximum dose of $5 \mathrm{mg}$ is recommended with a daily limit of $20 \mathrm{mg}$. Any potential local irritating effect may be reduced by dilution with syrup $B P$. The indiscriminate use of this drug for all manner of feeding problems is to be deprecated.

(Accepted 22 December 1983 )

Department of Paediatrics, Glan Clwyd District Hospital, Bodelwyddan, Clwyd LL18 5UJ

JEFF WILLIAMS, MRCP, DCH, consultant paediatrician

ROB WATKIN-JONES, MB, CHB, senior house officer in paediatrics

Correspondence to: Dr Jeff Williams.

\section{Clostridium welchii infection after amniocentesis}

Postabortal sepsis due to Clostridium welchii has been reported with an incidence of $0 \cdot 5-1 \cdot 0^{\circ}{ }_{0} .^{1}$ 'The overall mortality ranges from $50^{\circ} \%$ to $85^{\circ}$, and when haemolysis, disseminated intravascular coagulation, and renal failure are present the death rate is $70 \%$ despite adequate medical management. ${ }^{23}$ Amniocentesis is a safe procedure with a slight increase of $1.0-1.5 \%$ in the rate of fetal loss. ${ }^{4}$ Amnionitis after amniocentesis has been reported but at a rate of less than $0.1 \%{ }^{5}$

We report a case of $\mathrm{Cl}$ welchii infection in a patient who aborted after amniocentesis.

\section{Case report}

A 39 year old woman (gravida 3, para 0) booked at a district general hospital in June 1983. Amniocentesis was performed under ultrasound control at 16 weeks for chromosomal analysis. Two attempts to obtain liquor were unsuccessful and the fetal heart was observed before and after the procedure by ultrasound. The patient was admitted to hospital within 12 hours with an inevitable abortion and aborted a macerated, infected fetus.

Erythromycin and metronidazole were administered intravenously. Over the next few hours the patient's condition deteriorated. She became jaundiced, hypotensive, and hypoxic. She was intubated and intermittent positive pressure ventilation instituted. She rapidly became oliguric, passing small quantities of dark urine only. Exchange blood transfusion was followed by evacuation of retained products of conception. There was no improvement however, and she was transferred to the intensive care unit at this hospital 24 hours after admission.

Initial assessment confirmed disseminated intravascular coagulation, renal failure, haemolytic anaemia, shock lung, and Gram positive septicaemia. Cultures of blood and placental tissue subsequently confirmed infection by $\mathrm{Cl}$ welchii sensitive to erythromycin and metronidazole. A high vaginal swab taken before she aborted did not grow $\mathrm{Cl}$ welchii. Intermittent positive pressure ventilation was continued and haemodialysis performed. She was transfused with packed cells and fresh frozen plasma. Total abdominal hysterectomy and bilateral salpingectomy were performed six hours after admission because of continuing haemolysis and severe hypotension. The uterus appeared macroscopically intact but $\mathrm{Cl}$ welchii was cultured from the uterine cavity and myometrium. She gradually improved: the haemolysis stopped and her fever disappeared after 48 hours. She remained in renal failure, however, for which she required haemodialysis over the next four weeks. Five months after aborting her renal function was still impaired though she did not require dialysis.

\section{Comment}

Cl welchii is a Gram positive, anaerobic, non-motile, spore forming organism which is often encapsulated and capable of producing exotoxins. Among these are $\alpha$ toxin (lecithinase $\mathrm{C}$ ), which acts on the surfaces of red and white cells and is responsible for the intravascular haemolysis which causes anaemia and jaundice. It may also produce haemorrhage as a result of its necrotising action on capillaries and arteriolar walls.

$\mathrm{Cl}$ welchii may be recovered from the vagina and cervix in $1-9 \%$ of healthy pregnant women, but only a small proportion are virulent.' Septic abortion Jue to $C l$ welchii rarely occurs in clinical practice 